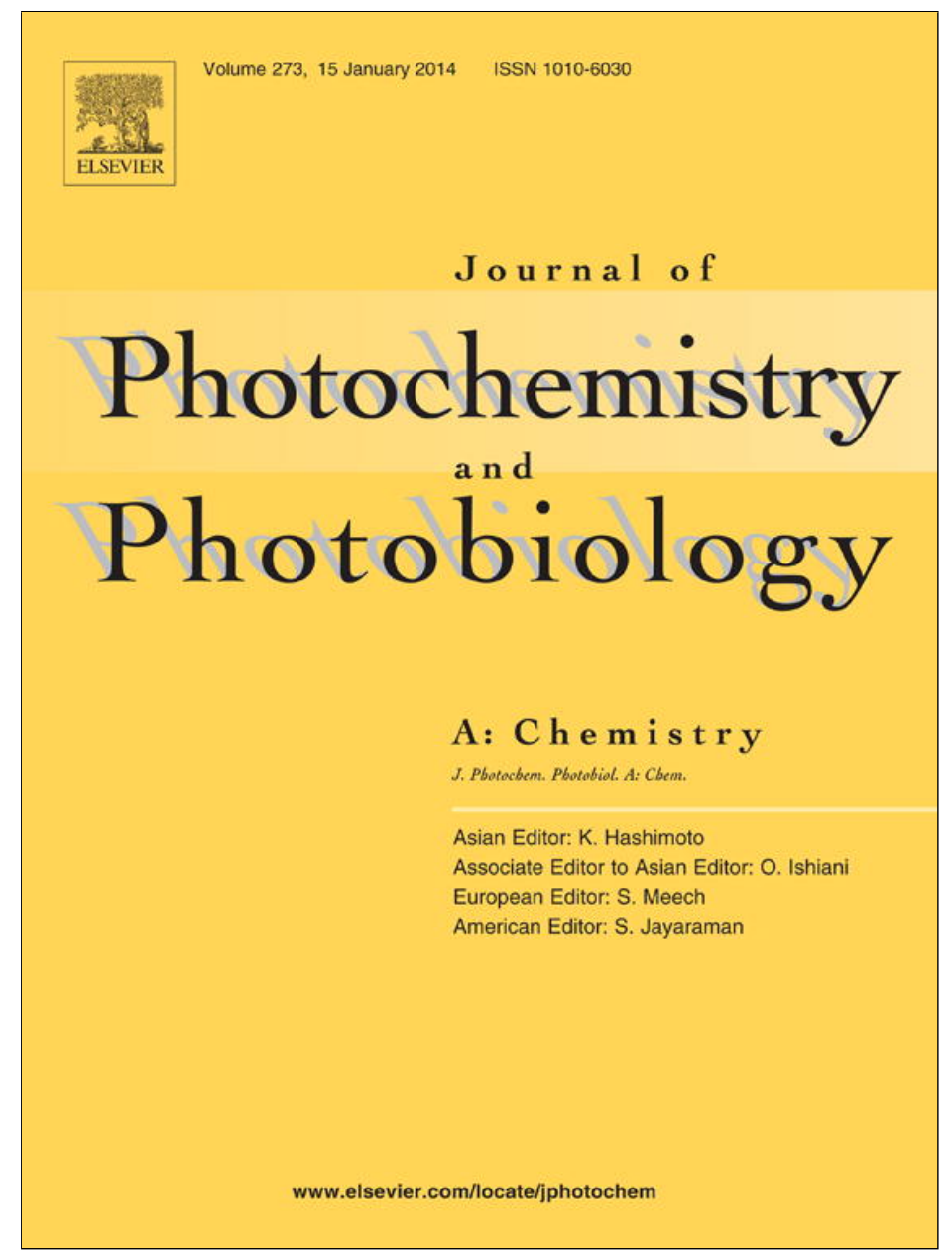

This article appeared in a journal published by Elsevier. The attached copy is furnished to the author for internal non-commercial research and education use, including for instruction at the authors institution and sharing with colleagues.

Other uses, including reproduction and distribution, or selling or licensing copies, or posting to personal, institutional or third party websites are prohibited.

In most cases authors are permitted to post their version of the article (e.g. in Word or Tex form) to their personal website or institutional repository. Authors requiring further information regarding Elsevier's archiving and manuscript policies are encouraged to visit:

http://www.elsevier.com/authorsrights 


\title{
Effect of phosphate buffer on the complexation and photochemical interaction of riboflavin and caffeine in aqueous solution: A kinetic study
}

\author{
Muhammad Ali Sheraz ${ }^{a}$, Sadia Hafeez Kazi ${ }^{a}$, Sofia Ahmed ${ }^{a}$, Tania Mirza ${ }^{a}$, Iqbal Ahmad ${ }^{a}$, \\ Maxim P. Evstigneev ${ }^{\mathrm{b}, \mathrm{c}, *}$
}

a Institute of Pharmaceutical Sciences, Baqai Medical University, Toll Plaza, Super Highway, Gadap Road, Karachi 74600, Pakistan

b Department of Physics, Sevastopol National Technical University, Universitetskaya str. 33, Sevastopol 99053, Crimea, Ukraine

' Department of Biological and Chemical Sciences, Belgorod State University, Pobeda str. 85, Belgorod 308015, Russia

\section{A R T I C L E I N F O}

\section{Article history:}

Received 28 June 2013

Received in revised form

11 September 2013

Accepted 14 September 2013

Available online 23 September 2013

\section{Keywords:}

Riboflavin

Caffeine

Phosphate buffer

Photoaddition

Photoreduction

Kinetics

\begin{abstract}
A B S T R A C T
A study of the photodegradation of $5 \times 10^{-5} \mathrm{M}$ riboflavin (RF) in $0.2-1.0 \mathrm{M}$ phosphate buffer in the presence and absence of $2.50 \times 10^{-4} \mathrm{M}$ caffeine at $\mathrm{pH}$ 6.0-8.0 has been carried out. RF in phosphate buffer is photodegraded simultaneously by normal photolysis (photoreduction) and photoaddition reactions giving rise to lumichrome (LC) and cyclodehydroriboflavin (CDRF) as the main final products, respectively. $\mathrm{RF}$ and its photoproducts, formylmethylflavin (FMF), lumiflavin (LF), LC and CDRF in degraded solution have been determined by a specific multicomponent spectrophotometric method with an accuracy of $\pm 5 \%$. The apparent first-order rate constants for the photodegradation of RF and for the formation of LC and CDRF are 5.47-15.05 $\times 10^{-3} \mathrm{~min}^{-1}, 1.06-8.30 \times 10^{-3} \mathrm{~min}^{-1}$ and 4.31-8.05 $\times 10^{-3} \mathrm{~min}^{-1}$, respectively. An increase in phosphate concentration leads to an increase in the rate of formation of CDRF and alters the photodegradation of RF in favor of the photoaddition reaction. This photoaddition reaction is further enhanced in the presence of caffeine which results in a further decrease of the fluorescence of RF in phosphate buffer. Caffeine may facilitate the photoaddition reaction by suppression of the photoreduction pathway of RF.
\end{abstract}

(C) 2013 Elsevier B.V. All rights reserved.

\section{Introduction}

Buffers are considered as an important component of chemical and pharmaceutical systems to achieve optimum stability of a compound or to perform a reaction under controlled condition of $\mathrm{pH}$, buffer concentration and ionic strength. In many cases, the buffers affect the stability of pharmaceutical compounds in aqueous solution [1-6]. Several studies have been carried out to evaluate the effect of buffer species on the photolysis of riboflavin (RF). These studies include the catalytic effect of acetate [7] and phosphate buffers [8-14] and the inhibitory effect of borate [15] and citrate buffers [16]. It has been shown that the monovalent phosphate ions $\left(\mathrm{H}_{2} \mathrm{PO}_{4}^{-}\right)$exert a catalytic effect on the normal photolysis or photoreduction (side-chain cleavage) of $\mathrm{RF}[11,17]$ and the divalent phosphate ions $\left(\mathrm{HPO}_{4}{ }^{2-}\right)$ on the photoaddition (side chain

\footnotetext{
* Corresponding author at: Department of Physics, Sevastopol National Technical University, Universitetskaya str. 33, Sevastopol 99053, Crimea, Ukraine.

Tel.: +38 067 9210912; fax: +38 692243590 .

E-mail address: max_evstigneev@mail.ru (M.P. Evstigneev).
}

cyclization) reactions of RF [9-14]. These two major pathways of the photodegradation of RF occur simultaneously depending on the $\mathrm{pH}$, buffer concentration and light intensity and wavelengths [9-14]. The rate of photoaddition reaction of RF at $\mathrm{pH} 7.0$ is more than twice of the photolysis reaction [11].

$\mathrm{RF}$ is known to form molecular complexes with caffeine [18-24] which causes the stabilization of RF and thus inhibits its rate of chemical [25] and photodegradation reactions [26,27] in aqueous solution. However, the previous studies deal only with the individual effect of caffeine (CF) [27], or the phosphate [11-14] on the photodegradation of RF. These studies do not provide information on the combined effect of $\mathrm{CF}$ and phosphate on the reaction.

CF molecules may enter the human body from various food sources in large amounts and, thereby, may influence RF function in organism. Hence, the knowledge of photochemical interaction of CF-RF is important for understanding their interaction in a biological system. The knowledge of the set of factors altering RF photodegradation in solution is also important in view of the positive synergistic effect of blue light and RF with respect to suppression of tumor cells growth in vivo [28] and the blue 
light-mediated DNA repair by photolysate enzymes containing flavin adenine dinucleotide (FAD) as cofactor [29].

The present work is based on the evaluation of the effects of $\mathrm{CF}$ and phosphate together on the photodegradation of RF and the role of $C F$ vis-a-vis phosphate in altering the rates of the reactions. The study provides kinetic evidence to support the view that $\mathrm{CF}$ is involved in modifying the role of phosphate to enhance the photodegradation of RF. This would facilitate the understanding of the interaction of CF-RF in phosphate buffer and its influence on structural orientation to cause a particular change in the mode of degradation reactions.

\section{Materials and methods}

RF, LC, LF and CF were obtained from Sigma-Aldrich Chemicals Co. (St. Louis, MD, USA). FMF, CMF and CDRF were prepared by the previously described methods, respectively [30,31]. All the reagents and solvents were of analytical grade or of the purest form available from Merck \& Co. (Whitestone Station, NJ, USA).

\subsection{Photolysis of $R F$}

The photolysis of $5 \times 10^{-5} \mathrm{M} \quad \mathrm{RF}$ solutions, containing $2.5 \times 10^{-4} \mathrm{M} \mathrm{CF}$ was carried out at $25 \pm 1{ }^{\circ} \mathrm{C}$ in the presence and absence of $0.2-1.0 \mathrm{M} \mathrm{Na}_{2} \mathrm{HPO}_{4}$ at $\mathrm{pH} 6.0-8.0$. The $\mathrm{pH}$ of the solution was adjusted with $1.0-5.0 \mathrm{M} \mathrm{HCl} / \mathrm{NaOH}$ solution. The solution $(100 \mathrm{ml})$ was irradiated in a dark chamber using a Philips $125 \mathrm{~W}$ high pressure mercury vapor fluorescent lamp (emission at 405 and $435 \mathrm{~nm}$ ), fixed horizontally at a distance of $30 \mathrm{~cm}$ from the center of the flask. The $435 \mathrm{~nm}$ band of the radiation source overlaps the $445 \mathrm{~nm}$ absorption maximum of RF [11] while CF $(\lambda \max 273 \mathrm{~nm})$ [32] does not absorb in the visible region. The solution was stirred by bubbling a stream of air into the flask. Samples were withdrawn at appropriate intervals for chromatographic examination and spectrophotometric determination. The photolysis of RF was also carried out under the same conditions in the presence of $1 \mathrm{M}$ phosphate and $0.625-2.50 \times 10^{-4} \mathrm{M} \mathrm{CF}$ at $\mathrm{pH}$ 7.0.

\subsection{Thin layer chromatography}

The identification of the photodegradation products of RF was carried out by thin-layer chromatography (TLC) using 250$\mu \mathrm{m}$ silica gel $\mathrm{G}$ plates (Merck) and the solvent systems: (a) 1-butanol-acetic acid/water (40:10:50 (v/v), organic phase) [33], and (b) chloroform-methanol $(9: 2(\mathrm{v} / \mathrm{v}))$ [9]. The detection of $\mathrm{RF}$ and its photodegradation products was performed by their characteristic fluorescence emission under UV $(365 \mathrm{~nm})$ excitation (RF, FMF, CMF - yellow green; LC, sky blue) using a Uvitech lamp (Cambridge, UK) or by visual examination (CDRF - red color). The progress of the photolysis reactions was monitored by observing the intensity variations of the spots of different products.

\subsection{Spectrophotometric assay}

The assay of RF and its side-chain cleavage photoproducts (FMF, LC, LF) and cycloaddition photoproduct (CDRF) was performed by a five component spectrophotometric method of Ahmad et al. [11]. This method has previously been used in a number of photodegradation studies of RF in the presence of phosphate buffer [11-14]. It involves the pre-adjustment of the photodegraded solutions to $\mathrm{pH} 2.0(0.2 \mathrm{M} \mathrm{HCl} / \mathrm{KCl}$ buffer $)$, followed by the extraction of $\mathrm{LC}$ and LF with chloroform and determination of the chloroform residue at $\mathrm{pH} 4.5$ ( $0.2 \mathrm{M}$ acetate buffer) by a two-component assay at 356 and $445 \mathrm{~nm}$, the respective absorption maxima of LC and LF [11]. The other three compounds (RF, FMF, CDRF), present in the aqueous phase, are determined by a three-component assay at $385,410,445 \mathrm{~nm}$, corresponding to the absorption maxima of FMF, CDRF and RF, respectively [11]. The absorption maxima of RF and FMF ( $445 \mathrm{~nm}, \mathrm{pH} 7.0$ ) can be distinguished at $\mathrm{pH} 2.0$ where FMF exists in a protonated form $\left(\mathrm{p} K_{\mathrm{a}} 3.5\right)$ [34] and thus can be assayed by this method. CMF is a minor product of the oxidation of FMF $[13,17,35]$ and has not been considered in the assay scheme.

\subsection{Spectral measurements}

The spectral and absorbance measurements on RF and its photolyzed solutions were performed on a Shimadzu UV-1601 recording spectrophotometer using quartz cells of $10-\mathrm{mm}$ path length.

\subsection{Fluorescence measurements}

The fluorescence of RF solutions was measured at room temperature $\left(25^{\circ} \mathrm{C}\right)$ with a Spectromax 5 fluorimeter (molecular devices, Sunnyvale, CA, USA) in the end point mode using $374 \mathrm{~nm}$ as the excitation wavelength and $525 \mathrm{~nm}$ as the fluorescence wavelength [36]. The fluorescence was measured in relative fluorescence units using a pure $0.05 \mathrm{mM}$ RF solution as the standard.

\subsection{Light intensity measurement}

The measurement of the intensity of Philips HPL-N $125 \mathrm{~W}$ high pressure mercury vapor fluorescent lamp was performed using potassium ferrioxalate actinometry [37]. The value of the intensity of the lamp was determined as $1.16 \pm 0.098 \times 10^{17}$ quanta $^{-1}$.

\section{Result and discussion}

\subsection{Composition of photodegraded solution of $R F$}

It is necessary to ascertain the nature of products formed in the photodegraded solutions of $\mathrm{RF}$ in the presence of phosphate buffer and $\mathrm{CF}$ at $\mathrm{pH}$ 6.0-8.0. TLC of the solutions using solvent system (a) showed the presence of the compounds $\left(R_{f}\right.$ values in parentheses): undergraded RF (0.36), FMF (0.61), LC (0.67), LF (0.42) and CMF (0.26), with their characteristic fluorescence emission (mentioned in Section 2 under thin layer chromatography), and solvent system (b): undergraded RF (0.37), LC (0.82) and CDRF (0.46) (red color). These products have previously been identified in the photodegradation of RF under similar conditions and arise from the photoreduction and photoaddition pathways [9,17,27,38]. The formation (FMF, LC, LF, CMF, CDRF) and loss (RF, FMF, CMF) of these compounds was monitored by changes in the intensity of their spots. The formation of LF in the reaction takes place at pH 7.0-8.0.

\subsection{Spectral characteristics of photodegraded solutions}

The spectral variations in the photodegraded solutions of RF in the presence of CF [27] and the phosphate buffer [9,11,14] have been studied. In the presence of CF, RF shows a loss of absorbance at 374 and $445 \mathrm{~nm}$ and a slight increase around $385 \mathrm{~nm}$ indicating the formation of FMF with time in the aqueous phase $(\mathrm{pH} 2.0)$ after chloroform extraction to remove LC and LF. The mixture of these products in the aqueous solution $(\mathrm{pH} 4.5)$ exhibits a gradual increase in absorbance around 356 and $445 \mathrm{~nm}$, the respective absorption maxima of LC and LF. The absorption spectrum of the photodegraded solutions of RF in the presence of phosphate buffer 
Table 1

Apparent first-order rate constants $\left(k_{\text {obs }}\right)$ for the photodegradation of RF and for the formation of CDRF $\left(k_{1}\right)$ and $\mathrm{LC}\left(k_{2}{ }^{\prime}\right)$ in the presence of $\mathrm{CF}\left(2.5 \times 10^{4} \mathrm{M}\right)$ and phosphate buffer $(0.2-1.0 \mathrm{M})$ at different $\mathrm{pH}$ values ${ }^{\mathrm{a}}$.

\begin{tabular}{|c|c|c|c|c|c|}
\hline $\mathrm{pH}$ & Phosphate conc. (M) & $k_{\mathrm{obs}} \times 10^{3}\left(\mathrm{~min}^{-1}\right) \pm \mathrm{SD}$ & $k_{1} \times 10^{3}\left(\mathrm{~min}^{-1}\right) \pm \mathrm{SD}$ & $k_{2}^{\prime} \times 10^{3}\left(\mathrm{~min}^{-1}\right) \pm \mathrm{SD}$ & $k_{1} / k_{2}^{\prime}$ \\
\hline \multirow[t]{6}{*}{6.0} & 0.2 & $5.69 \pm 0.28$ & - & - & - \\
\hline & 0.4 & $7.49 \pm 0.45$ & - & - & - \\
\hline & 0.6 & $8.76 \pm 0.46$ & - & - & - \\
\hline & 0.8 & $9.94 \pm 0.62$ & - & - & - \\
\hline & 1.0 & $11.17 \pm 0.60$ & - & - & - \\
\hline & & $(5.14 \pm 0.21)$ & - & - & - \\
\hline \multirow[t]{6}{*}{6.5} & 0.2 & $5.43 \pm 0.24$ & $1.12 \pm 0.07$ & $4.31 \pm 0.26$ & 0.26 \\
\hline & 0.4 & $6.76 \pm 0.34$ & $2.19 \pm 0.11$ & $4.57 \pm 0.25$ & 0.48 \\
\hline & 0.6 & $8.83 \pm 0.40$ & $3.70 \pm 0.22$ & $5.13 \pm 0.32$ & 0.72 \\
\hline & 0.8 & $10.40 \pm 0.69$ & $4.99 \pm 0.32$ & $5.41 \pm 0.33$ & 0.92 \\
\hline & 1.0 & $11.70 \pm 0.70$ & $6.05 \pm 0.35$ & $5.65 \pm 0.28$ & 1.07 \\
\hline & & $(6.15 \pm 0.29)$ & $(1.35 \pm 0.05)$ & $(4.80 \pm 0.21)$ & $(0.28)$ \\
\hline \multirow[t]{6}{*}{7.0} & 0.2 & $5.87 \pm 0.32$ & $1.53 \pm 0.08$ & $4.32 \pm 0.28$ & 0.36 \\
\hline & 0.4 & $7.92 \pm 0.51$ & $2.81 \pm 0.14$ & $5.11 \pm 0.31$ & 0.55 \\
\hline & 0.6 & $10.99 \pm 0.55$ & $4.85 \pm 0.29$ & $6.14 \pm 0.36$ & 0.79 \\
\hline & 0.8 & $13.18 \pm 0.71$ & $6.68 \pm 0.30$ & $6.50 \pm 0.26$ & 1.03 \\
\hline & 1.0 & $15.05 \pm 0.90$ & $8.30 \pm 0.42$ & $6.75 \pm 0.39$ & 1.23 \\
\hline & & $(8.13 \pm 0.43)$ & $(3.23 \pm 0.19)$ & $(4.90 \pm 0.28)$ & $(0.66)$ \\
\hline \multirow[t]{6}{*}{7.5} & 0.2 & $8.85 \pm 0.57$ & $2.15 \pm 0.15$ & $6.70 \pm 0.40$ & 0.32 \\
\hline & 0.4 & $10.73 \pm 0.60$ & $3.43 \pm 0.24$ & $7.30 \pm 0.37$ & 0.47 \\
\hline & 0.6 & $11.85 \pm 0.53$ & $4.49 \pm 0.27$ & $7.36 \pm 0.38$ & 0.61 \\
\hline & 0.8 & $13.12 \pm 0.79$ & $5.52 \pm 0.33$ & $7.60 \pm 0.34$ & 0.73 \\
\hline & 1.0 & $14.98 \pm 0.82$ & $6.92 \pm 0.38$ & $8.05 \pm 0.55$ & 0.86 \\
\hline & & $(5.81 \pm 0.33)$ & $(1.88 \pm 0.12)$ & $(3.93 \pm 0.26)$ & $(0.48)$ \\
\hline \multirow[t]{6}{*}{8.0} & 0.2 & $5.47 \pm 0.33$ & $1.06 \pm 0.04$ & $4.41 \pm 0.29$ & 0.24 \\
\hline & 0.4 & $6.57 \pm 0.43$ & $1.70 \pm 0.10$ & $4.87 \pm 0.29$ & 0.35 \\
\hline & 0.6 & $7.59 \pm 0.44$ & $2.31 \pm 0.12$ & $5.28 \pm 0.26$ & 0.44 \\
\hline & 0.8 & $9.31 \pm 0.47$ & $3.26 \pm 0.19$ & $6.05 \pm 0.39$ & 0.54 \\
\hline & 1.0 & $10.25 \pm 0.62$ & $4.03 \pm 0.22$ & $6.21 \pm 0.41$ & 0.65 \\
\hline & & $(4.88 \pm 0.32)$ & $(1.32 \pm 0.07)$ & $(3.56 \pm 0.15)$ & $(0.37)$ \\
\hline
\end{tabular}

a The values of the rate constants in parentheses are in the absence of $\mathrm{CF}$ in $1.0 \mathrm{M}$ phosphate buffer.

( $\mathrm{pH}$ 7.0) show the loss of RF around $445 \mathrm{~nm}$ and the formation of LC and CDRF around 356 and $410 \mathrm{~nm}$, respectively [14]. The absorption spectra of RF solution (aqueous phase), photodegraded in the presence and absence of $\mathrm{CF}$ in phosphate buffer ( $\mathrm{pH}$ 7.0) exhibit similar spectral variations indicating the loss of RF and the formation of FMF and CDRF by different pathways. It is interesting to note that the $410 / 445 \mathrm{~nm}$ (CDRF/RF) ratio in the presence and absence of CF in $1 \mathrm{M}$ phosphate buffer on photodegradation in $2 \mathrm{~h}$ changes from 0.63 to 3.90 and 0.63 to 2.70 , respectively (Fig. 1). This indicates a two-fold increase in the absorbance ratio leading to the formation of CDRF in the presence of CF. A three-component analysis of the spectral data in the presence and absence of $\mathrm{CF}$ and their kinetic treatment in terms of the rate constants (Table 1 ) indicates the effect of CF on the rates of the reactions. The magnitude of spectral variations depends on the concentration of phosphate buffer which alters the normal photolysis (photoreduction) pathway (leading to the formation of FMF, LC and LF by cleavage of the ribityl side-chain) in favor of the photoaddition pathway (leading to the formation of CDRF by cyclophotoaddition of the ribityl side-chain).

\subsection{Assay of RF and photoproducts}

The photodegraded solutions of RF represent a complex mixture containing RF, FMF, LC, LF and CDRF in a variable composition and need a specific, convenient and reliable method for the assay of RF and its photodegradation products. In a previous study [9], no quantitative and kinetic study of these reactions has been carried out. Ahmad et al. [11] developed a multicomponent spectrophotometric method for the assay of RF, FMF, LC, LF and CDRF in the photodegradation of RF in the presence of phosphate buffer and applied it to the kinetic studies of the reaction [11-14]. Ahmad and Rapson [39] had previously reported a similar spectrophotometric method for the assay of RF, FMF, LC and LF in the photodegraded solutions of RF. This method has extensively been applied to study the kinetics of normal photolysis of RF in aqueous solution in the absence [15-17] and presence of CF [27].

The assay method used in this study [11] takes into consideration the simultaneous determination of RF and its photodegradation products of normal photolysis (FMF, LC and LF) and photoaddition (CDRF). This method would throw light on the relative composition of the photodegradation product of the two reaction pathways and has previously been used for similar studies in the absence of CF [11-14]. CF $\left(\lambda_{\max } 273 \mathrm{~nm}\right)$ does not interfere in the region of wavelengths used for the assay of RF and its photoproducts [27].

\subsection{Kinetics of photodegradation reactions}

The photodegradation of RF takes place by several pathways including the photoreduction, photoaddition and photodealkylation $[10,14,40-42]$. In the presence of divalent phosphate ions $\left(\mathrm{HPO}_{4}{ }^{2-}\right)$, RF undergoes simultaneous photoreduction and photoaddition reactions in aqueous solution to form LC and CDRF, respectively, as the main final photoproducts [9,11-14]. The rates of these reactions depend on the condition such as $\mathrm{pH}$, buffer concentration and light intensity. The photodegradation of RF in the presence of phosphate buffer can be expressed by the following reactions: 


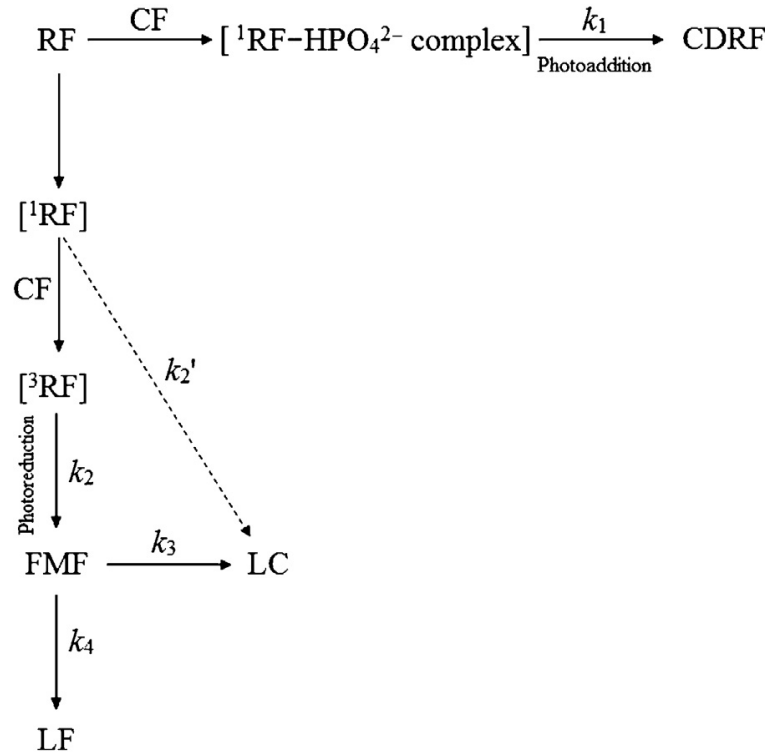

Since the amount of LF formed at pH 7.0-8.0 is less than $5 \%$ of the reaction mixture at $50 \%$ photodegradation of RF, it could be omitted in the above scheme. LC is formed through FMF as an intermediate in this reaction, it could be assumed that CDRF and LC are formed by parallel first-order reactions. Therefore, the values of $k_{1}$ and $k_{2}{ }^{\prime}$ can be determined from the values of $k_{\mathrm{obs}}$,

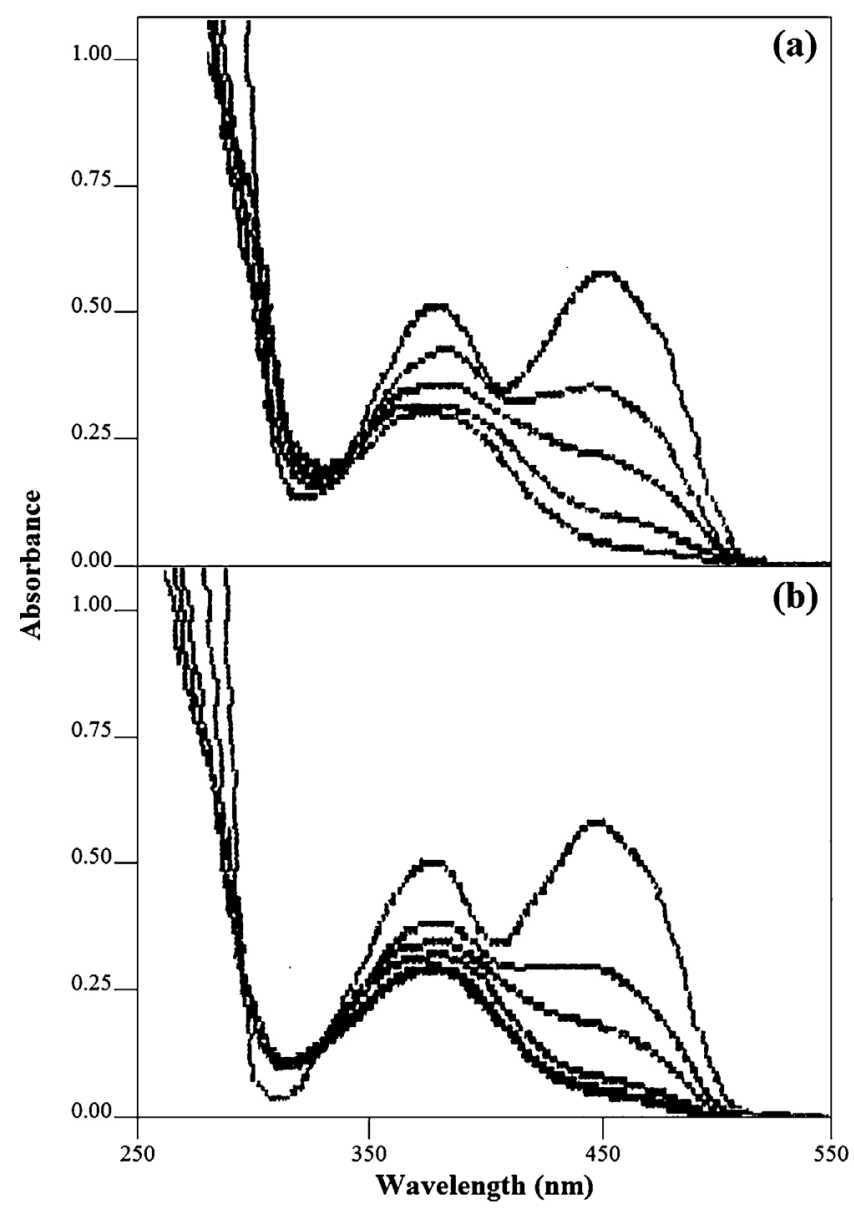

Fig. 1. UV and visible absorption spectra of photodegraded solutions of $\mathrm{RF}$ at $\mathrm{pH} 7.0$ (1.0 M phosphate buffer). (a) In the presence of CF and (b) in the absence of CF at 0 , $30,60,90$ and $120 \mathrm{~min}$. the overall first-order rate constant for the photodegradation of RF. The mathematical treatment of differential equations for the reactant and the products, the determination of the values of $k_{1}$ and $k_{2}{ }^{\prime}$ (considering direct formation of LC from RF) and the determination of $k_{3}{ }^{\prime}$ and $k_{4}{ }^{\prime}$ for the $\mathrm{H}_{2} \mathrm{PO}_{4}{ }^{-}$and $\mathrm{HPO}_{4}{ }^{2-}$ ions catalyzed reactions has been dealt in an earlier communication $[5,11,14]$. The values of $k_{\mathrm{obs}}, k_{1}$ and $k_{2}{ }^{\prime}$ in the presence of $\mathrm{CF}$ along with the values in the absence of $\mathrm{CF}$ in $1.0 \mathrm{M}$ phosphate buffer are reported in Table 1 . The values of $k_{4}{ }^{\prime}$ have been determined from the plots of $k_{\text {obs }}$ versus $\mathrm{H}_{2} \mathrm{PO}_{4}^{-}$/Total phosphate concentration. This value in the presence of $\mathrm{CF}\left(2.29 \times 10^{-2} \mathrm{M}^{-1} \mathrm{~min}^{-1}\right)$ is nearly twice of the value $\left(1.39 \times 10^{-2} \mathrm{M}^{-1} \mathrm{~min}^{-1}\right)$ in the absence of $\mathrm{CF}$ in $1.0 \mathrm{M}$ phosphate buffer. This indicates that CF accelerates the photoaddition pathway of RF. This is further substantiated by the values of $k_{1} / k_{2}^{\prime}$ in the presence and absence of CF as discussed under Section 3.6.

\subsection{Effect of phosphate buffer}

Previous studies of the effect of phosphate buffer on the photodegradation of RF have indicated the simultaneous formation of CDRF and LC by different pathways. The rates of these reactions depend on the concentration of phosphate species present at a particular $\mathrm{pH}$ [11-14]. In the present study the photodegradation reactions of $\mathrm{RF}$ in phosphate buffer have been carried out in the presence or absence of CF. A consideration of the reaction in $1.0 \mathrm{M}$ phosphate buffer alone at $\mathrm{pH} 7.0$ shows that the ratio of the first-order rate constants for the formation of CDRF (photoaddition) and LC (photoreduction) $\left(k_{1} / k_{2}^{\prime}\right)$ is 0.66 , i.e., one-third of the photodegradation reaction leads to the formation of CDRF and two-third to the formation of LC. This is the same pattern as observed in the earlier studies of the effect of phosphate buffer on the photodegradation of $\operatorname{RF}[11,12,14]$. This ratio has been found to increase with an increase in buffer concentration in the presence of $2.5 \times 10^{-4} \mathrm{M} \mathrm{CF}(0.36-1.23)$ indicating an enhancement in the rate of photodegradation pathway of RF in favor of the photoaddition reaction (Table 1 ).

\subsection{Effect of CF and phosphate buffer}

An increase in $\mathrm{CF}$ concentration at a fixed concentration of phosphate buffer $(1.0 \mathrm{M})$ also resulted in an increase in the ratios of $k_{1} / k_{2}^{\prime}(0.70-1.23)$ (Table 2), suggesting that CF in the presence of phosphate buffer influences the photoaddition pathway. This could be due to the suppression of the photoreduction pathway as observed in a previous study [27]. In the presence of CF, the $k_{1} / k_{2}{ }^{\prime}$ ratio is twice (1.23) compared to that observed in the presence of phosphate buffer alone (0.66) at $\mathrm{pH}$ 7.0. Thus, in addition to the suppression of the photoreduction pathway of RF, CF may be involved in some interaction with phosphate buffer to accelerate the photoaddition reaction. CF forms molecular complexes with $\mathrm{RF}$ (see Section 1) and thus inhibits its rate of chemical [25] and photodegradation reactions $[26,27]$ in aqueous solutions. It has been suggested that $\mathrm{CF}$ forms a hetero association complex with flavin mononucleotide (FMN) as a result of vertical stacking interaction between the aromatic chromophores of the two molecules [24,43]. In view of the formation of such an association complex between $\mathrm{CF}$ and RF and the fact that an increase in CF concentration would cause greater suppression of the photoreduction pathway [27], an acceleration in the photoaddition pathway is expected as evident from the values of $k_{1}$ and $k_{2}{ }^{\prime}$. It is interesting to know that the values of $k_{1} / k_{2}{ }^{\prime}$ in the presence of CF are higher than these obtained in the absence of CF. Therefore, CF appears to exert an influence in determining the magnitude of the two degradation pathways of RF.

The observed ability of CF molecule to discriminate between different degradation pathways of RF, found in the present work and linked with the stacking-type hetero-complex formation, is 
Table 2

Apparent first-order rate constants $\left(k_{\mathrm{obs}}\right)$ for the photodegradation of RF and for the formation of $\mathrm{CDRF}\left(k_{1}\right)$ and $\mathrm{LC}\left(k_{2}{ }^{\prime}\right)$ in the presence of $\mathrm{CF}\left(0.625-2.50 \times 10^{4} \mathrm{M}\right)$ in phosphate buffer $(1.0 \mathrm{M})$ at $\mathrm{pH} 7.0$.

\begin{tabular}{lccc}
\hline Caffeine concentration $\left(\mathrm{M} \times 10^{4}\right)$ & $k_{\text {obs }} \times 10^{3}\left(\mathrm{~min}^{-1}\right) \pm \mathrm{SD}$ & $k_{1} \times 10^{3}\left(\mathrm{~min}^{-1}\right) \pm \mathrm{SD}$ & $k_{2}{ }^{\prime} \times 10^{3}\left(\mathrm{~min}^{-1}\right) \pm \mathrm{SD}$ \\
\hline 0.625 & $8.42 \pm 0.51$ & $3.47 \pm 0.19$ & $4.95 \pm 0.35$ \\
1.250 & $11.11 \pm 0.67$ & $5.10 \pm 0.33$ & $6.01 \pm 0.36$ \\
1.875 & $12.86 \pm 0.75$ & $6.53 \pm 0.39$ & 0.70 \\
2.500 & $15.05 \pm 0.90$ & $8.30 \pm 0.42$ & 1.03 \\
\hline
\end{tabular}

very similar to well-known regulatory action of $\mathrm{CF}$ with respect to aromatic drugs binding with DNA [44,45] and antibiotic-vitamin interaction [46], which is also considered as a consequence of the hetero-association between $\mathrm{CF}$ and other molecular species in solution. The likely reason for the influence of the hetero-complex formation on the kinetics of RF photodegradation is the formation of low dielectric environment within the volume of hetero-complex as a consequence of water exclusion, altering the energetic barriers for chemical transformation of RF. This effect, being specific to stacking type of interactions, is also known to result in a variety of biochemical effects such as, for instance, the lowering of $\mathrm{p} K_{\mathrm{a}}$ of certain atomic groups within the complexes [47], changing the drugs' pharmacokinetics [48] and solubility [49].

\subsection{Effect of $p H$}

The present study of the photodegradation of RF has been carried out at $\mathrm{pH}$ 6.0-8.0. The rate of $\mathrm{HPO}_{4}{ }^{2-}$ ion catalyzed reaction is highest around pH 7 as observed earlier $[9,11,14]$. An essential requirement for the intramolecular photoaddition of $\mathrm{RF}$ is that it occurs at $\mathrm{pH}$ value $>6$ [9]. This is in accordance with the name assigned to the reaction as the anion-catalyzed neutral photochemistry by the discoverers [9] and has been found in this study. The rate of reaction increases with $\mathrm{pH}$ up to a maximum $(\mathrm{pH} 7)$ and then decreases as observed in a previous study [14]. The same pattern of reaction is observed in the presence of $\mathrm{CF}$, however, the value of $k_{\text {obs }}$ is nearly twice than that obtained in the absence of CF (Fig. 2). This shows that CF plays a significant role in the photodegradation of RF in phosphate buffer. This would further be explained in the next section.

\subsection{Fluorescence studies}

Fluorescence studies on RF solutions in the presence of CF and phosphate buffer have been carried out to observe their effect on the intensity of fluorescence emission (Table 3). RF exhibits intense yellow green fluorescence in aqueous solution [41,50,51]. The fluorescence of a $5 \times 10^{-5} \mathrm{M}$ RF solution ( $\mathrm{pH} 7.0$ ) is not affected by $1.25-2.50 \times 10^{-4} \mathrm{M}$ CF. However, it is decreased by about $19 \%$ in

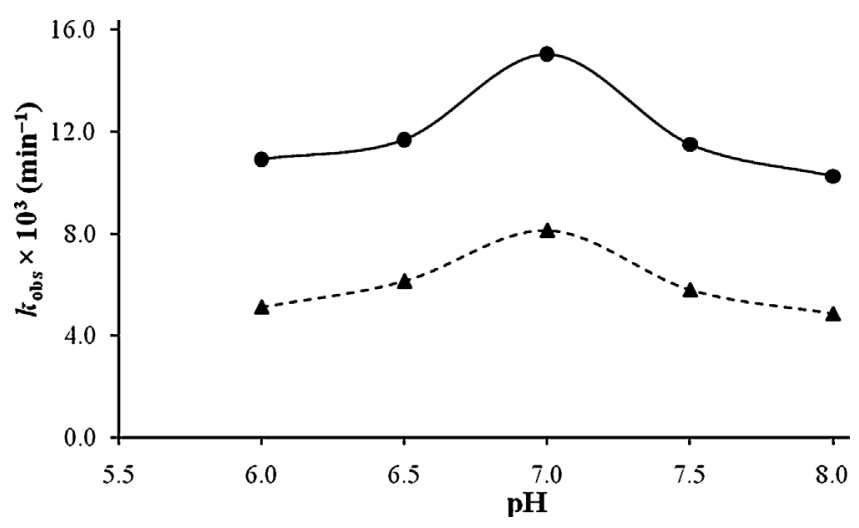

Fig. 2. Plots of $k_{\mathrm{obs}}$ versus pH for the photodegradation of RF in $1.0 \mathrm{M}$ phosphate buffer solutions in the presence $(-\bullet-)$ and absence $(-\boldsymbol{\Delta}-)$ of $\mathrm{CF}\left(2.50 \times 10^{4} \mathrm{M}\right)$.
Table 3

Fluorescence intensity of $5 \times 10^{-5} \mathrm{M}$ RF solution at $\mathrm{pH} 7.0$ in the presence of $\mathrm{CF}$ and phosphate buffer ${ }^{\mathrm{a}}$.

\begin{tabular}{lll}
\hline $\begin{array}{l}\text { Caffeine concentration } \\
\left(\mathrm{M} \times 10^{4}\right)\end{array}$ & $\begin{array}{l}\text { Phosphate } \\
\text { concentration }(\mathrm{M})\end{array}$ & $\begin{array}{l}\text { Relative fluorescence } \\
\text { intensity at } 525 \mathrm{~nm}\end{array}$ \\
\hline 0.00 & 0.005 & 100.0 \\
1.25 & 0.005 & 100.0 \\
2.50 & 0.005 & 100.0 \\
0.00 & 1.00 & 81.1 \\
1.25 & 1.00 & 78.0 \\
2.50 & 1.00 & 74.6 \\
\hline
\end{tabular}

a Measurements were made at ambient temperature $\left(\sim 25^{\circ} \mathrm{C}\right)$ under aerobic conditions.

the presence of $1.0 \mathrm{M}$ phosphate buffer as observed in a previous study [12]. The addition of $2.50 \times 10^{-4} \mathrm{M} \mathrm{CF}$ to this solution further decreases the fluorescence of RF to the extent of about $6 \%$. Since CF alone does not affect the fluorescence of RF and its presence in RF solutions containing phosphate buffer leads to a further decrease in the fluorescence intensity, some interaction between $\mathrm{CF}$ and phosphate buffer may be stipulated. The fact that the first-order rate constants for the formation of CDRF are faster in phosphate buffer containing CF compared to those of the phosphate buffer alone (Table 1) and the values increase with an increase in phosphate concentration suggests that some interaction takes place between $\mathrm{CF}$ and phosphate ions to facilitate the reaction (photoaddition pathway). The loss of fluorescence of RF in the presence of phosphate buffer alone indicates an interaction between RF and phosphate ions (Table 3). This interaction could result from a $\mathrm{RF}-\mathrm{HPO}_{4}{ }^{2-} \mathrm{com}-$ plex in the excited singlet state $\left({ }^{1} \mathrm{RF}\right)$ as suggested by Schuman Jorns et al. [9], to promote the photoaddition pathway. A further decrease in RF fluorescence in phosphate buffer in the presence of CF (6\%) suggests that $\mathrm{CF}$ plays a role in the enhancement of the reaction leading to the photoaddition pathway.

In addition to the formation of a molecular complex between RF and $\mathrm{CF}$ to inhibit the degradation reaction, there is a possibility of the suppression of the photoreduction pathway by deactivation of the excited triplet state $\left({ }^{3} \mathrm{RF}\right)$. CF could quench ${ }^{3} \mathrm{RF}$ by an electron transfer in phosphate buffer and thus facilitate the photoaddition pathway. This is substantiated by a relatively little increase in $k_{2}{ }^{\prime}$ with an increase in $\mathrm{CF}$ concentration compared to that of $k_{1}$ in the overall photodegradation ( $\left.k_{\mathrm{obs}}\right)$ of $\mathrm{RF}$ (Table 2 ). CF may influence the other pathways of photodegradation of RF. It has been suggested that the formation of $\mathrm{LC}$ also takes place by the participation of ${ }^{1} \mathrm{RF}$ in the intramolecular photoreduction [38] and the intramolecular photodealkylation reactions $[40,42]$ of flavins. However, the predominant reaction in phosphate buffer involves the photoaddition of RF giving rise to CDRF. Further structural studies are required to ascertain the exact role of $\mathrm{CF}$ in the kinetics of degradation of RF.

\section{Conclusion}

The photodegradation of riboflavin in phosphate buffer at $\mathrm{pH}$ 6.0-8.0 occurs by simultaneous photoreduction (side chain cleavage) and photoaddition (side chain cyclization) pathways. The rates of these reactions depend on the concentration of phosphate buffer. An increase in phosphate concentration alters the 
photodegradation of riboflavin in favor of the photoaddition pathway and the highest rate of the reaction occurs around $\mathrm{pH} 7$. Both $\mathrm{H}_{2} \mathrm{PO}_{4}^{-}$and $\mathrm{HPO}_{4}{ }^{2-}$ ions catalyze the photodegradation of $\mathrm{RF}$ by photoreduction (LC) and photoaddition (CDRF) pathways, respectively. The addition of caffeine to riboflavin solutions in phosphate buffer has been found to influence the photodegradation of riboflavin by inhibiting the photoreduction pathway and enhancing the photoaddition pathway. Caffeine could interact with ${ }^{3} \mathrm{RF}$ in phosphate to cause suppression of the photoreduction pathway and thus facilitate the formation of CDRF as observed during these studies, and/or directly interact with RF within the RF-CF stackingtype hetero-complex altering the energetic barriers for chemical transformation of RF.

\section{References}

[1] J.T. Carstensen, Kinetic pH profiles, in: J.T. Carstensen, C.T. Rhodes (Eds.), Drug Stability Principles and Practices, 3rd ed., Marcel Dekker, New York, USA, 2000, pp. 73-84.

[2] P.J. Sinko, Martin's Physical Pharmacy and Pharmaceutical Sciences, 5th ed., Lippincott Williams \& Wilkins, Baltimore, USA, 2006, pp. 406-407, $416-420$.

[3] S. Yoshioka, V.J. Stella, Stability of Drugs and Dosage Forms, Kluwer Academic/Plenum Publishers, New York, USA, 2000, pp. 97-99.

[4] J.K. Guillory, R.I. Poust, Chemical kinetics and drug stability, in: G.S. Banker, C.T Rhodes (Eds.), Modern Pharmaceutics, 4th ed., Marcel Dekker, New York, USA 2002, pp. 158-159.

[5] A.T. Florence, D. Attwood, Physicochemical Principles of Pharmacy, 4th ed., Pharmaceutical Press, London, UK, 2006, pp. 113-118.

[6] L. Lachman, P. DeLuca, M.J. Akers, Kinetic principles and stability testing, in: L. Lachman, H.A. Lieberman, J.L. Kanig (Eds.), The Theory and Practice of Industrial Pharmacy, 3rd ed., Lea \& Febiger, Philadelphia, USA, 1986, pp. 768-769.

[7] M. Halwer, The photochemistry of riboflavin and related compound, J. Am. Chem. Soc. 73 (1951) 4870-4874.

[8] B. Holmstrom, Mechanism of the photoreduction of riboflavin, Arkiv. Kemi. 22 (1964) 329-346.

[9] M. Schuman Jorns, G. Schollnhammer, P. Hemmerich, Intramolecular addition of the riboflavin side chain, anion-catalysed neutral photochemistry, Eur. J. Biochem. 57 (1975) 35-48.

[10] I. Ahmad, F.H.M. Vaid, Photochemistry of flavins in aqueous and organic solvents, in: E. Silva, A.M. Edwards (Eds.), Flavins Photochemistry and Photobiology, Royal Society of Chemistry, Cambridge, UK, 2006, pp. $13-40$.

[11] I. Ahmad, Q. Fasihullah, F.H.M. Vaid, A study of simultaneous photolysis and photoaddition reactions of riboflavin in aqueous solution, J. Photochem. Photobiol. B: Biol. 75 (2004) 13-20.

[12] I. Ahmad, Q. Fasihullah, F.H.M. Vaid, Effect of phosphate buffer on photodegradation reactions of riboflavin in aqueous solution, J. Photochem. Photobiol. B: Biol. 78 (2005) 229-234.

[13] I. Ahmad, Q. Fasihullah, F.H.M. Vaid, Effect of light intensity and wavelengths on photodegradation reactions of riboflavin in aqueous solution, J. Photochem. Photobiol. B: Biol. 82 (2006) 21-27.

[14] I. Ahmad, S. Ahmed, M.A. Sheraz, F.H.M. Vaid, I.A. Ansari, Effect of divalent anions on photodegradation kinetics and pathways of riboflavin in aqueous solution, Int. J. Pharm. 390 (2010) 174-182

[15] I. Ahmad, S. Ahmed, M.A. Sheraz, F.H.M. Vaid, Effect of borate buffer on the photolysis of riboflavin in aqueous solution, J. Photochem. Photobiol. B: Biol. 93 (2008) 82-87.

[16] I. Ahmad, S. Ahmed, M.A. Sheraz, S.H. Kazi, T. Mirza, M. Aminuddin, Stabilizing effect of citrate buffer on the photolysis of riboflavin in aqueous solution, Results Pharma. Sci. 1 (2011) 11-15.

[17] I. Ahmad, Q. Fasihullah, A. Noor, I.A. Ansari, Q.N.M. Ali, Photolysis of riboflavin in aqueous solution: a kinetic study, Int. J. Pharm. 280 (2004) 199-208.

[18] J.E. Wilson, Studies on the electronic nature of flavin-indole and flavin-purine complexes, Biochemistry 5 (1966) 1351-1359.

[19] E. DeRitter, Vitamins in pharmaceutical formulations, J. Pharm. Sci. 71 (1982) 1073-1096.

[20] R.S. Rivlin, Riboflavin (vitamin B2), in: J. Zempleni, R.B. Rucker, D.B. McCormick, J.W. Suttie (Eds.), Handbook of Vitamins, 4th ed., Taylor \& Francis, CRC Press, Boca Raton, FL, USA, 2007, pp. 233-251.

[21] D.E. Guttman, M.Y. Athalye, Solubilization of riboflavin by complex formation with caffeine, theophylline and dimethyluracil, J. Am. Pharm. Assoc. Sci. Ed. 49 (1960) 687-691.

[22] G.R. Penzer, G.K. Radda, The chemistry and biological functions of isoalloxazines (Flavins), Q. Rev. 21 (1967) 43-65.
[23] J.C.M. Tsibris, D.B. McCormick, L.D. Wright, Donor-acceptor complexes relating to the intramolecular association of the riboflavin and adenosine moieties of flavin adenine dinucleotide, Biochemistry 4 (1965) 504-510.

[24] M.P. Evstigneev, A.O. Rozvadovskaya, A.A. Hernandez Santiago, Y.V. Mukhina, K.A. Veselkov, O.V. Rogova, D.B. Davies, A.N. Veselkov, A ${ }^{1}$ H NMR study of the association of caffeine with flavin mononucleotide in aqueous solution, Russ. J. Phys. Chem. 79 (2005) 573-578.

[25] D.E. Guttman, Complex formation influence on reaction rate, I. Effect of caffeine on riboflavin base-catalyzed degradation rate, J. Pharm. Sci. 51 (1962) $1162-1166$.

[26] Y. Sato, M. Yokoo, S. Takahashi, T. Takahashi, Biphasic photolysis of riboflavin with a low-intensity light source, Chem. Pharm. Bull. 30 (1982) 1803-1810.

[27] I. Ahmad, S. Ahmed, M.A. Sheraz, M. Aminuddin, F.H.M. Vaid, Effect of caffeine complexation on the photolysis of riboflavin in aqueous solution: a kinetic study, Chem. Pharm. Bull. 57 (2009) 1363-1370.

[28] M. Ohara, T. Fujikura, H. Fujiwara, Augmentation of the inhibitory effect of blue light on the growth of B16 melanoma cells by riboflavin, Int. J. Oncol. 22 (2003) $1291-1295$.

[29] C.W.M. Kay, A. Bacher, M. Fischer, G. Richter, E. Schleicher, S. Weber, Blue light-initiated DNA repair by photolyase, in: E. Silva, A.M. Edwards (Eds.), Flavins-Photochemistry and Photobiology, Royal Society of Chemistry, Cambridge, UK, 2006, pp. 151-182.

[30] C. Fukumachi, Y. Sakurai, Vitamin B2 photolysis, V. The photolytic formation of 6,7-dimethylflavin-9-acetic acid ester from riboflavin, Vitamins (Kyoto) 7 (1954) 939-943.

[31] H.H. Fall, H.G. Petering, Metabolic inhibitors, 1,6,7-dimethyl-9formylmethylisoalloxazine, 6,7-dimethyl-9-(2-hydroxyethyl)-isoalloxazine and derivatives, J. Am. Chem. Soc. 78 (1956) 377-381.

[32] A.C. Moffat, M.D. Osselton, B. Widdop, Clarke's Analysis of Drugs and Poisons, 4th ed., Pharmaceutical Press, London, UK, 2011, pp. 1028-1029.

[33] G.E. Treadwell, W.L. Cairns, D.E. Metzler, Photochemical degradation of flavins, V. Chromatographic studies of the products of photolysis of riboflavin, J. Chromatogr. 35 (1968) 376-388.

[34] C.H. Suelter, D.E. Metzler, The oxidation of a reduced pyridine nucleotide analog by flavins, Biochim. Biophys. Acta 44 (1960) 23-33.

[35] I. Ahmad, T. Mirza, K. Iqbal, S. Ahmed, M.A. Sheraz, F.H.M. Vaid, Effect of pH buffer, and viscosity on the photolysis of formylmethylflavin: a kinetic study, Aust. J. Chem. 66 (2013) 579-585.

[36] P.S. Song, D.E. Metzler, Photochemical degradation of flavins, IV. Studies of the anaerobic photolysis of riboflavin, Photochem. Photobiol. 6 (1967) 691-709.

[37] C.G. Hatchard, C.A. Parker, A new sensitive chemical actinometer, II. Potassium ferrioxalate as a standard chemical actinometer, Proc. R. Soc. (Lond.) A 235 (1956) 518-536

[38] W.L. Cairns, D.E. Metzler, Photochemical degradation of flavins, VI. A new photoproduct and its use in studying photolytic mechanism, J. Am. Chem. Soc. 93 (1971) 2772-2777.

[39] I. Ahmad, H.D.C. Rapson, Multicomponent spectrophotometric assay of riboflavin and photoproducts, J. Pharm. Biomed. Anal. 8 (1990) 217-223.

[40] P.S. Song, Chemistry of flavins in their excited states, in: H. Kamin (Ed.), Flavins and Flavoprotein, University Park Press, Baltimore, USA, 1971, pp. 37-61.

[41] P.F. Heelis, The photophysical and photochemical properties of flavins (isoalloxazines), Chem. Soc. Rev. 11 (1982) 15-39.

[42] P.F. Heelis, The photochemistry of flavins, in: F. Muller (Ed.), Chemistry and Biochemistry of Flavoenzymes, vol. 1, CRC Press, Boca Raton, FL, USA, 1991, pp. $171-193$.

[43] P.A. Bolotin, S.F. Baranovsky, D.N. Chernyshev, M.P. Evstigneev, Spectrophotometric study of the solution interactions between riboflavin, sodium salicylate and caffeine, Int. J. Phys. Sci. 2 (2007) 68-72.

[44] E. Bedner, L. Du, F. Traganos, Z. Darzynkiewicz, Caffeine dissociates complexes between DNA and intercalating drugs: application for bleaching fluorochromestained cells for their subsequent restaining and analysis by laser scanning cytometry, Cytometry 43 (2001) 38-45.

[45] M.P. Evstigneev, A.O. Lantushenko, V.P. Evstigneev, Yu.V. Mykhina, D.B. Davies, Quantitation of the molecular mechanisms of biological synergism in a mixture of DNA-acting aromatic drugs, Biophys. Chem. 132 (2008) 148-158.

[46] M.P. Evstigneev, V.P. Evstigneev, D.B. Davies, NMR investigation of the effect of caffeine on the hetero-association of an anticancer drug with a vitamin, Chem. Phys. Lett. 432 (2006) 248-251.

[47] N.A. Corfù, H. Sigel, Acid-base properties of nucleosides and nucleotides as a function of concentration, Eur. J. Biochem. 199 (1991) 659-669.

[48] V.C. Okore, A.C. Osuji, A model study on caffeine-paracetamol interactions, Acta Pharm. 51 (2001) 139-145.

[49] M.P. Evstigneev, V.P. Evstigneev, A.A. Hernandez Santiago, D.B. Davies, Effect of a mixture of caffeine and nicotinamide on the solubility of vitamin $\left(B_{2}\right)$ in aqueous solution, Eur. J. Pharm. Sci. 28 (2006) 59-66.

[50] British Pharmacopoeia, Monograph on Riboflavin, Her Majesty's Stationary Office, London, UK, 2013, Electronic version.

[51] P. Drossler, W. Holzer, A. Penzkofer, P. Hegemann, pH dependence of the absorption and emission behaviour of riboflavin in aqueous solution, Chem. Phys. 282 (2002) 429-439. 